\title{
Effect of Data Length on Rainfall-runoff Modelling
}

\author{
By W. C. Boughton* \\ Griffith University, Brisbane, Australia
}

* Address: 11 Preston Place, Brookfield, Qld., Australia

Tel.: $\quad$ +61-7-3374-4785

E-mail: $\quad$ wboughto@bigpond.net.au

\begin{abstract}
A 64-year data set of daily rainfall and runoff, and average monthly potential evapotranspiration (PET) was split into subsets of 2, 5, 10, 20 and 30 years. Each subset was used to calibrate the AWBM daily rainfall-runoff model. Each subset calibration was then used to estimate runoff from the 64 years of rainfall and PET data. The ratios of calculated to actual total runoff were used to determine probabilities of error from the different lengths of data used for calibration. There was little difference in results from the 2 and 5 year subsets with 10\% chance of error in estimating long term runoff in the range of $-21 \%$ to $+31 \%$. The probabilities of overestimating long term runoff reduced with length of calibration data of $10+$ years; however, the chances of underestimating were above $15 \%$ even with 30 years of calibration data. Some limited repetition of the calculations with the Curve Number rainfall-runoff model indicated that the error characteristics were inherent in the data set and not an artifact of the model used. The ramifications for applications of rainfall-runoff modelling are briefly discussed.
\end{abstract}

Keywords: hydrologic modelling, rainfall-runoff, catchments, watersheds

\section{Introduction}

Continuous simulation of the water balance of catchments is now a major tool for relating runoff to rainfall for water yield studies (Boughton 2005) and for loss estimation in flood studies (Boughton and Droop 2003). Computer simulation models are calibrated to a concurrent period of rainfall and runoff data, and a longer period of rainfall data or a long period of stochastically generated rainfall data are used to estimate a longer period of runoff.

There is an implied assumption that the runoff processes represented by the model will be the same in the shorter and longer periods, and the calibration based on the shorter period will be the same in the longer period. In practice, periods of data as short as 2 years are used to estimate long term runoff. This raises some doubt about the accuracy of the long term estimate, but there is little information available about such accuracy. There are some recommendations in the literature for split sampling, i.e. use half of the data for calibration and the other half for testing the accuracy of estimation. This approach has little value when only very short periods of data are available. 
Australia is rich in mineral resources, but these are often located in sparsely populated regions where streamgauging data are unavailable. It is not unusual for a mining company to establish a gauging station at a mining site when approval for the project is given, resulting in one or two years of data being available when planning for essential water supplies must be made for a project involving expenditure of some hundreds of millions of dollars.

The present study was designed to examine the probabilities of error from calibrating a daily rainfall-runoff model to short periods of data and then using a longer period of rainfall data to estimate runoff in the longer period. A data set with 64 years of rainfall and runoff data was selected so that calibrations based on sub-periods of the data could be compared with the recorded 64 years of runoff.

\section{Data}

The data used in this study are from the $407 \mathrm{~km}^{2}$ Snowy Creek catchment below Granite Flat, streamgauging station 401210, a tributary of the Mitta Mitta River in the Upper Murray basin in north east Victoria. There were 64 years of data, 1933-1996, available for analysis. Average annual rainfall, runoff and potential evapotranspiration (PET) were $1372 \mathrm{~mm}, 492 \mathrm{~mm}$ and $1022 \mathrm{~mm}$ respectively. The ratio of runoff to rainfall is 0.36 .

The data set was previously used in a project for the National Land and Water Resources Audit (Peel et al. 2001; Chiew et al. 2002) and in another study by Boughton and Chiew (2003). The source of the daily rainfall data is the Queensland Department of Natural Resources \& Mining $0.05^{\circ}$ x $0.05^{\circ}$ (about $5 \mathrm{~km}$ x $5 \mathrm{~km}$ ) interpolated gridded rainfall data based on over 6000 rainfall stations in Australia (see www.dnr.qld.gov.au/silo). The interpolation uses Ordinary Krigging of monthly rainfall data, and a variogram with zero nugget and a variable range. The monthly rainfall for each $5 \mathrm{~km} \times 5 \mathrm{~km}$ point is then disaggregated to daily rainfall using the daily rainfall distribution from the station closest to the point. The lumped catchment-average daily rainfall is estimated from the daily rainfall in $5 \mathrm{~km} \times 5 \mathrm{~km}$ points within the catchment.

Compared to rainfall, evapotranspiration has little influence on the water balance at a daily time scale. The inter-annual variability of PET is also relatively small (typically less than 0.05). For these reasons, the mean monthly areal PET is used. The 12 mean monthly areal PET values are obtained from the evapotranspiration maps produced jointly by the Cooperative Research Centre for Catchment Hydrology and the Australian Bureau of Meteorology (Australian Bureau of Meteorology 2001; and www.bom.gov.au/climate/averages ). The areal PET values are derived using Morton's complementary relationship model (Morton 1983; Chiew and McMahon 1991).

The data from the Snowy Creek catchment are of good quality. A preliminary calibration of the AWBM to the entire 64 years gave a coefficient of efficiency of 0.871 from a comparison of actual and modeled monthly runoff, and 0.796 from a comparison of yearly totals. The data were checked for any inconsistencies between rainfall and runoff, 
but no major errors were found. For sake of brevity, the average annual runoff based on the 64 years of record is used as "the long term runoff".

\section{AWBM Model}

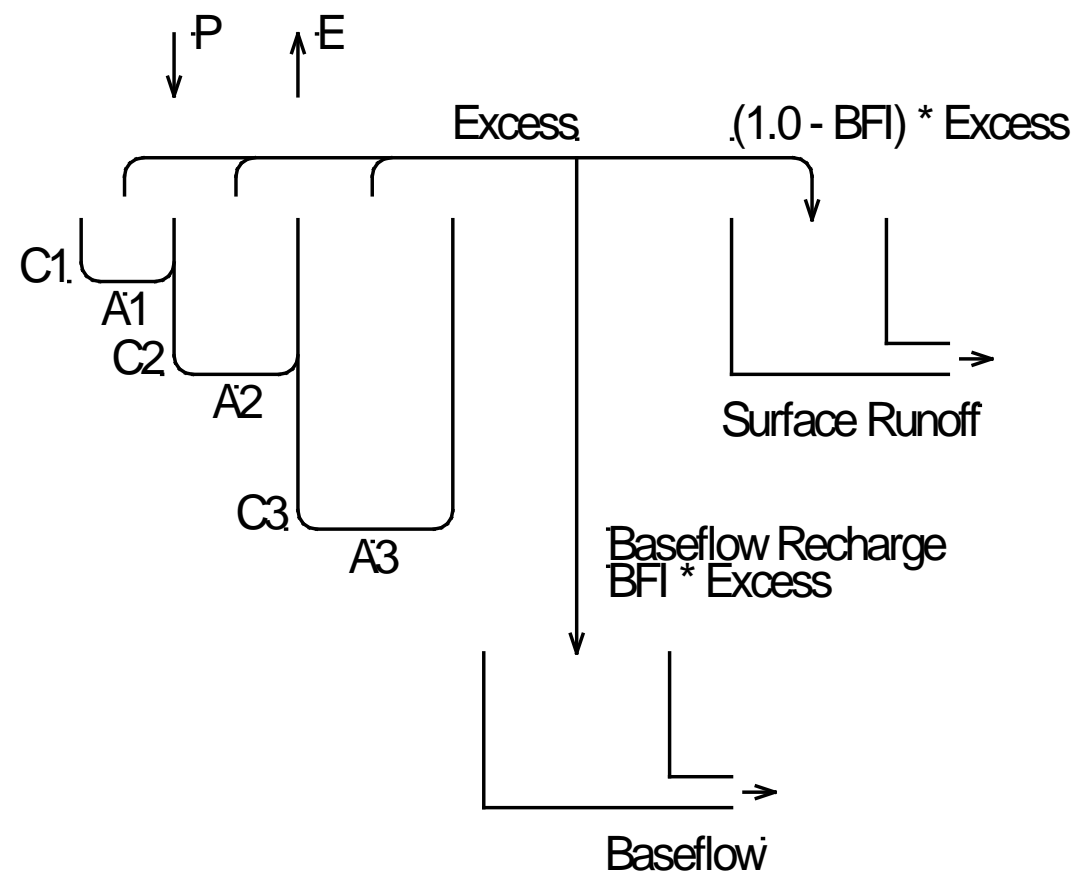

Figure 1 Structure of the AWBM model

The AWBM catchment water balance model (Boughton 2004) is used to estimate daily, monthly and annual runoff from a daily rainfall record and PET estimates. The model calculates surface runoff and baseflow components of streamflow at daily time steps. The AWBM generates runoff by saturation excess from three surface stores that allow for partial area runoff. The surface storage parameters are the three capacities and their partial areas, and the two baseflow parameters are the baseflow index (BFI) that determines how much of the runoff is baseflow, and the baseflow recession constant $\left(\mathrm{K}_{\mathrm{b}}\right)$ that determines how fast the water is discharged from the baseflow store. The structure of the model is shown in Figure 1.

The AWBM2002 version of the model self-calibrates to a data set of daily rainfall, daily runoff and monthly (or average monthly) PET, and this version was used for all calibrations. It uses a fixed pattern of the surface storage capacities and partial areas, such that a single parameter (average surface storage capacity) determines the amount of runoff. The average surface storage capacity is varied until total calculated runoff equals total actual runoff.

\section{Method}


The method is illustrated by use of the 10-year subsets of data. Every possible 10-year sub-period within the 64 years of data was tested. Starting with years 1 to 10, then 2 to 11 , and finally 55 to 64 , there were 55 sub-periods each 10 years in length. The AWBM was calibrated to each sub-period in turn. Each of these calibrations was then used with the 64 years of rainfall and PET data to estimate runoff for the data period. Each estimate of average annual runoff was then divided by the actual average from the 64 years of runoff to give a ratio of modeled runoff to actual runoff. For example, the calibration based on the sub-period years 1 to 10 estimated an average annual runoff of $540 \mathrm{~mm} / \mathrm{yr}$ from the 64 years of rainfall and PET data, compared with the recorded average of 492 $\mathrm{mm} / \mathrm{yr}$, i.e. a ratio of 1.097.

Figure 2 shows the ratio of 1.097 as the first of the 55 estimates that are summarized in the figure. The ratios varied from the lowest of 0.771 in the period starting in year 23 to the maximum of 1.241 in the very last sub-period.

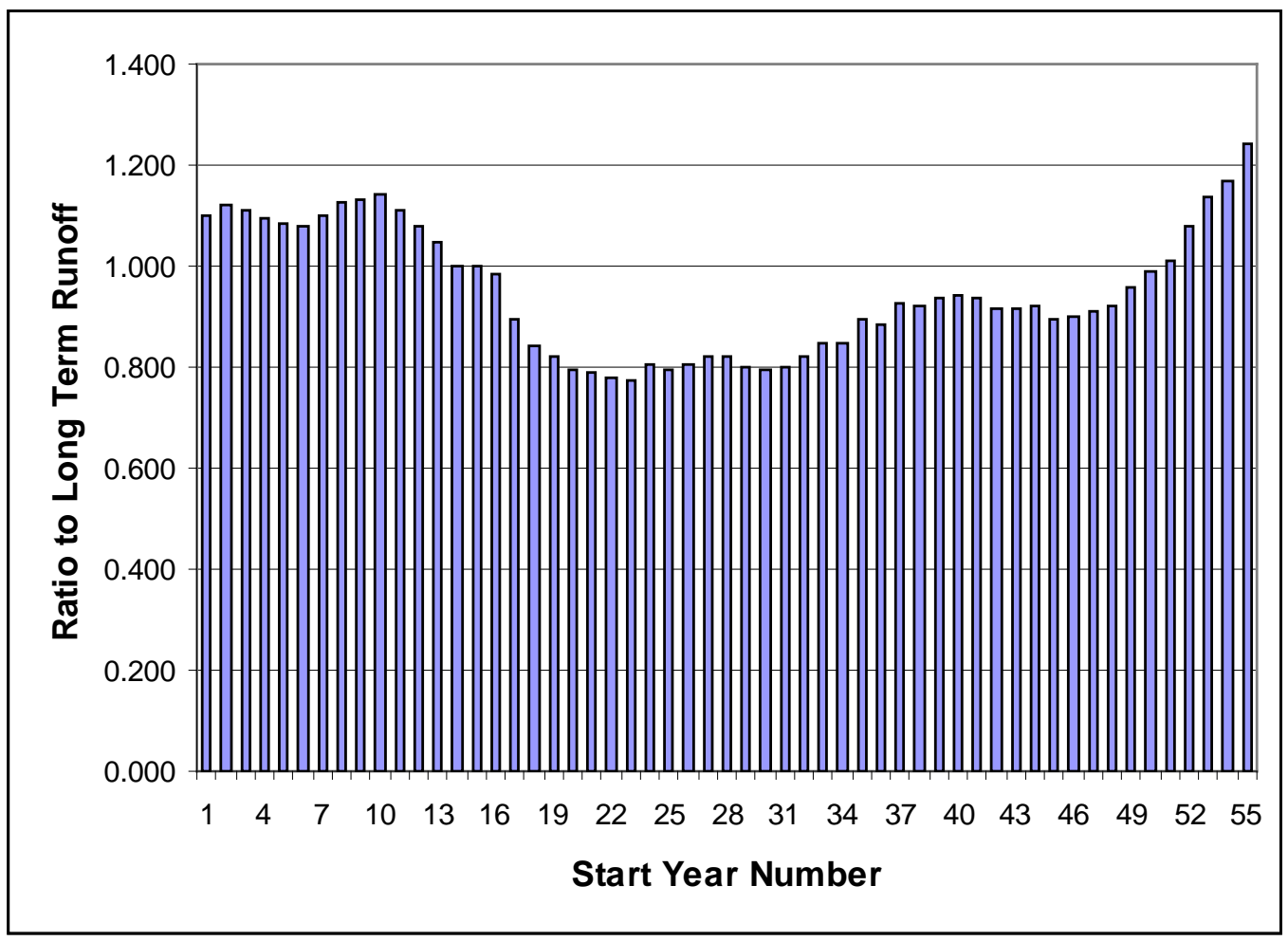

Figure 2 Ratios of modeled to actual average annual runoff from 55 10-year sub-periods.

It is more useful to deal with the results as a frequency distribution of the ratios from which probabilities of exceedance of various ratios can be determined. Figure 3 shows the frequency distribution of the 55 ratios based on the 10-year sub-periods. The distribution summarizes the probabilities of error if only 10 years of data are available for calibration. For example, $80 \%$ of the values (in the range $0.10-0.90$ ) are between the average annual runoff values of 557 to $390 \mathrm{~mm} / \mathrm{yr}$, i.e. within $+13.2 \%$ to $-20.7 \%$ of the 
actual average. So there is a $20 \%$ chance that estimates of long term runoff based on 10 years of data could be in error by more than $+13.2 \%$ or $-20.7 \%$. Similarly, using the $90 \%$ range between 0.05 and 0.95 exceedance probability, there is a $10 \%$ chance that the estimate could be in error by $+14.4 \%$ or $-21.3 \%$, and a $5 \%$ chance ( 0.025 to 0.975 ) that the estimate could be in error by $+19.9 \%$ or $-22.6 \%$.

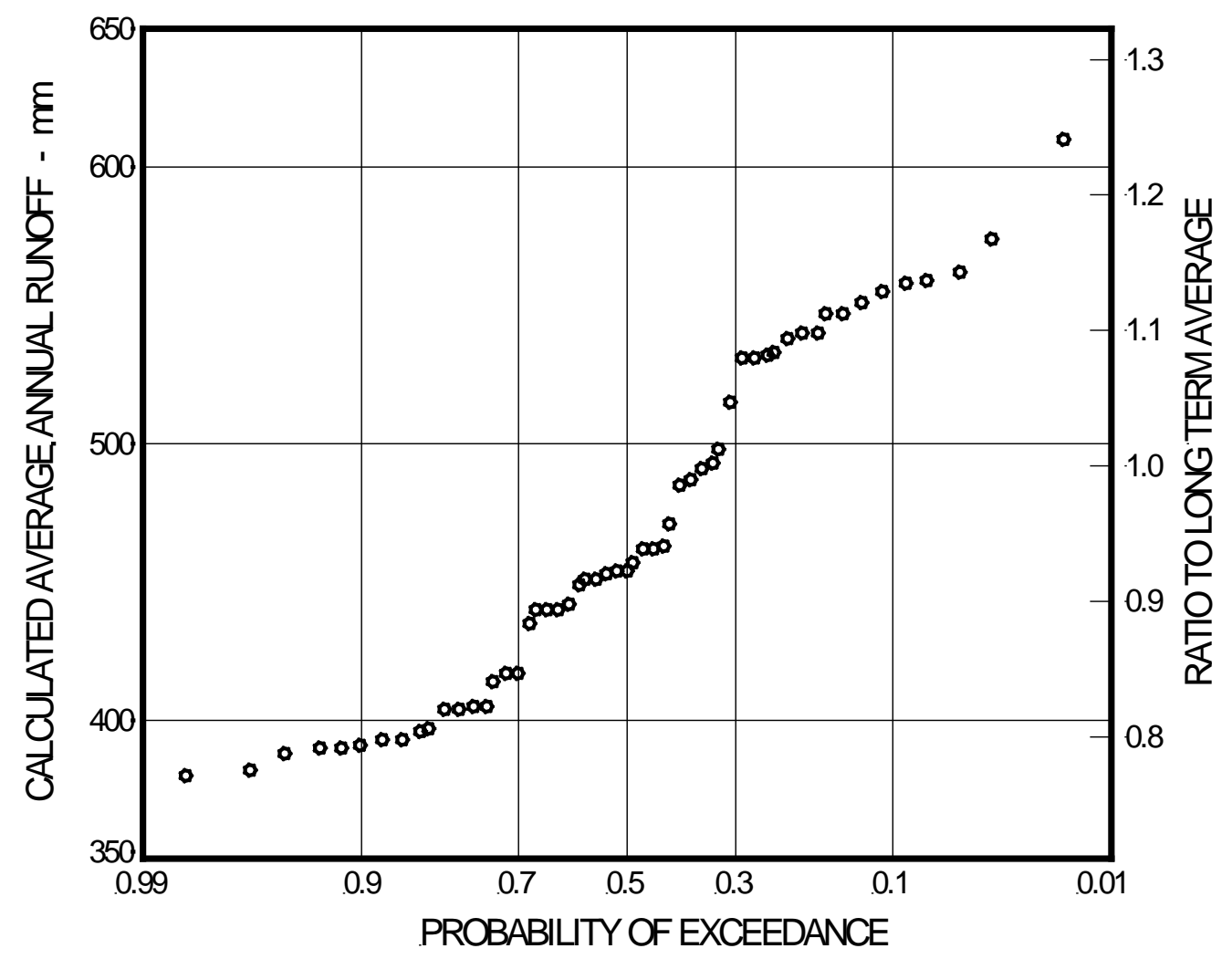

Figure 3. Frequency distribution of estimates of average annual runoff based on 10-year sub-periods

The method outlined above with 10-year sub-periods was then repeated with 4 other subperiods to determine how the probabilities of error vary if different lengths of data are available for the initial calibration - see next section.

\section{Results}

\section{Errors in estimates of average annual runoff}

The calculations demonstrated with 10-year sub-periods in the previous section were repeated with data periods of 2, 5, 20 and 30 years, and the probabilities of error were determined. There were 63 sub-sets of 2 years duration, 60 of 5 years, 45 of 20 years and 35 of 30 years. The probabilities are summarized in Table 1 . For example, if 2 years of data are available for calibration and the calibration is used with the 64 years of rainfall and PET data, then $95 \%$ of the estimates of average annual runoff will be within the 
range $+36.2 \%$ to $-23.0 \%$, i.e. there is a $5 \%$ chance that the estimate will be outside this range if only 2 years of data are available for calibration.

TABLE 1. Probabilities of Error in Estimate of Runoff for Various Lengths of Calibration Data.

\begin{tabular}{|c|c|c|c|}
\hline $\begin{array}{c}\text { Calibration data } \\
\text { length } \\
\text { Years }\end{array}$ & \multicolumn{2}{|c|}{$\begin{array}{c}\text { Ranges of error in estimate of runoff for percent chance of } \\
\text { error greater than range }\end{array}$} \\
\cline { 2 - 4 } & $\mathbf{5 \%}$ & $\mathbf{1 0 \%}$ & $\mathbf{2 0 \%}$ \\
\hline 2 & $+36.2 \%$ to $-23.0 \%$ & $+31.5 \%$ to $-22.2 \%$ & $+20.9 \%$ to $-21.1 \%$ \\
\hline 5 & $+35.6 \%$ to $-22.6 \%$ & $+30.1 \%$ to $-21.5 \%$ & $+16.7 \%$ to $-20.7 \%$ \\
\hline 10 & $+19.9 \%$ to $-22.6 \%$ & $+14.4 \%$ to $-21.3 \%$ & $+13.2 \%$ to $-20.7 \%$ \\
\hline 20 & $+11.0 \%$ to $-21.5 \%$ & $+9.3 \%$ to $-21.0 \%$ & $+1.2 \%$ to $-15.9 \%$ \\
\hline 30 & $+2.6 \%$ to $-16.5 \%$ & $+1.2 \%$ to $-15.9 \%$ & 0 to $-15.5 \%$ \\
\hline
\end{tabular}

The error ranges are very similar for 2 and 5 years of calibration data for each of the 5\%, $10 \%$ and $20 \%$ probability columns in Table 1 , which is contrary to expectation. The potential for overestimation of long term runoff (“+” error range) reduces significantly when 10 or more years of calibration data are available, but the potential for underestimation (“-“ error range) remains high even when 20 years of calibration data are available. The similarity of the error ranges among the 5\%, $10 \%$ and $20 \%$ probability ranges have a geometric explanation in the flat ends of the probability distribution in Figure 3.

The error values for 30 years of calibration data give an indication of the likely differences that would be experienced in split sampling testing of a rainfall-runoff model with the Snowy Creek data. The 30-year subsets are close to half of the 64 years of data and so simulate a split sample. The underestimates of about $16 \%$ and overestimates of 1 $2 \%$ are the maximum differences that could be expected if the Snowy Creek data were used for a split sample test of a rainfall-runoff model.

\section{Baseflow parameters}

In the automatic self-calibration version of the AWBM, the amount of runoff is determined by a single parameter, the average surface storage capacity. The two baseflow parameters, BFI and $\mathrm{K}_{\mathrm{b}}$, affect the temporal pattern of the runoff but do not affect the amount. In addition, the baseflow parameters affect the distribution of daily flows but have only a small effect on monthly totals of runoff.

The results shown in 'Errors in estimates of average annual runoff' deal with the amount of runoff in terms of average annual runoff. In order to examine the effect of short periods of data on baseflow parameters, the parameter values were collated for all 2-year and 5-year sub-sets. 
When the AWBM was calibrated to the total 64 years of record, the values of the baseflow parameters were BFI $=0.63$ (determined to the nearest 0.01 ) and $\mathrm{K}_{\mathrm{b}}=0.990$ (determined to the nearest 0.001 ). In the 63 sub-sets of 2-year periods, 57 calibrated the BFI to 0.63 and only 6 to another value. The other values were one each of $0.62,0.61$, $0.600 .57,0.56$ and 0.55 . For the baseflow recession constant, $K_{b}, 62$ of the 63 values were within 0.004 of the long term value of 0.990 , and one value was 0.983 . The biggest errors of BFI $=0.55$ and $\mathrm{K}_{\mathrm{b}}=0.983$ have such a small effect on the monthly totals of runoff that it would be difficult to express the difference in any meaningful way.

In the 60 sub-sets of 5 -year periods, 57 values of the BFI were the same as the full calibration (0.63). The other three values were $0.62,0.60$ and 0.59 . All values of the baseflow recession constant $\mathrm{K}_{\mathrm{b}}$ were within 0.004 of the full calibration value of 0.990 .

There was little purpose in extending the study to the longer sub-sets. It is clear that short periods of data are much better at estimating the long term values of the baseflow parameters than at estimating the average surface storage capacity that determines the amount of runoff.

\section{Repeat results with a different model}

The amount of modelling work in the study is too daunting for much repetition with different models; however, it was possible to repeat enough with a different rainfallrunoff model to demonstrate that the results are inherent in the data and are not a feature of the model.

Fortuitously, a computer program for calibration of the USDA SCS Curve Number model (SCS 1985), using the same format of input data as the AWBM, was available. To examine the difference between the two models, the Curve Number model was calibrated to each of the 55 10-year sub-periods in the same manner as the AWBM in 'Method'.

To obtain sufficient accuracy for the purpose, it was necessary to calibrate the curve numbers to the nearest 0.1 . In the normal manner, calibration was made of the curve number for middle antecedent moisture (CN2) and the CN1 and CN3 determined from the published relationships with CN2 (Ponce and Hawkins 1996). Calibration was made to match the total calculated runoff with total actual runoff in each 10-year period. Each calibration from a 10-year period was then used with the 64 years of rainfall data to estimate 64 years of runoff. This was divided by the actual runoff to give a ratio of calculated to actual runoff. Figure 4 shows the ratios from the 55 sub-sets of data using the Curve Number model.

Figure 4 based on the Curve Number is very similar to Figure 2 that shows the same results from the AWBM. The two temporal patterns of change in the ratio from start to finish of the data set are very similar. The regions of ratios $>1.0$ and ratios $<1.0$ occur in similar areas of the two graphs. 
The calibration of CN2 for the entire 64 years of data was 95.5, which is higher than the range of CN2 in published recommendations. Calibrations of CN2 in the individual 10year sub-periods ranged from 94.0 to 96.7. When used with the 64 years of data, these gave estimates of long term runoff of $394 \mathrm{~mm} / \mathrm{yr}$ and $599 \mathrm{~mm} / \mathrm{yr}$, equal to $-20 \%$ and $+22 \%$. This range of error is very similar to that produced by the AWBM $(-21 \%$ to $+14 \%)$.

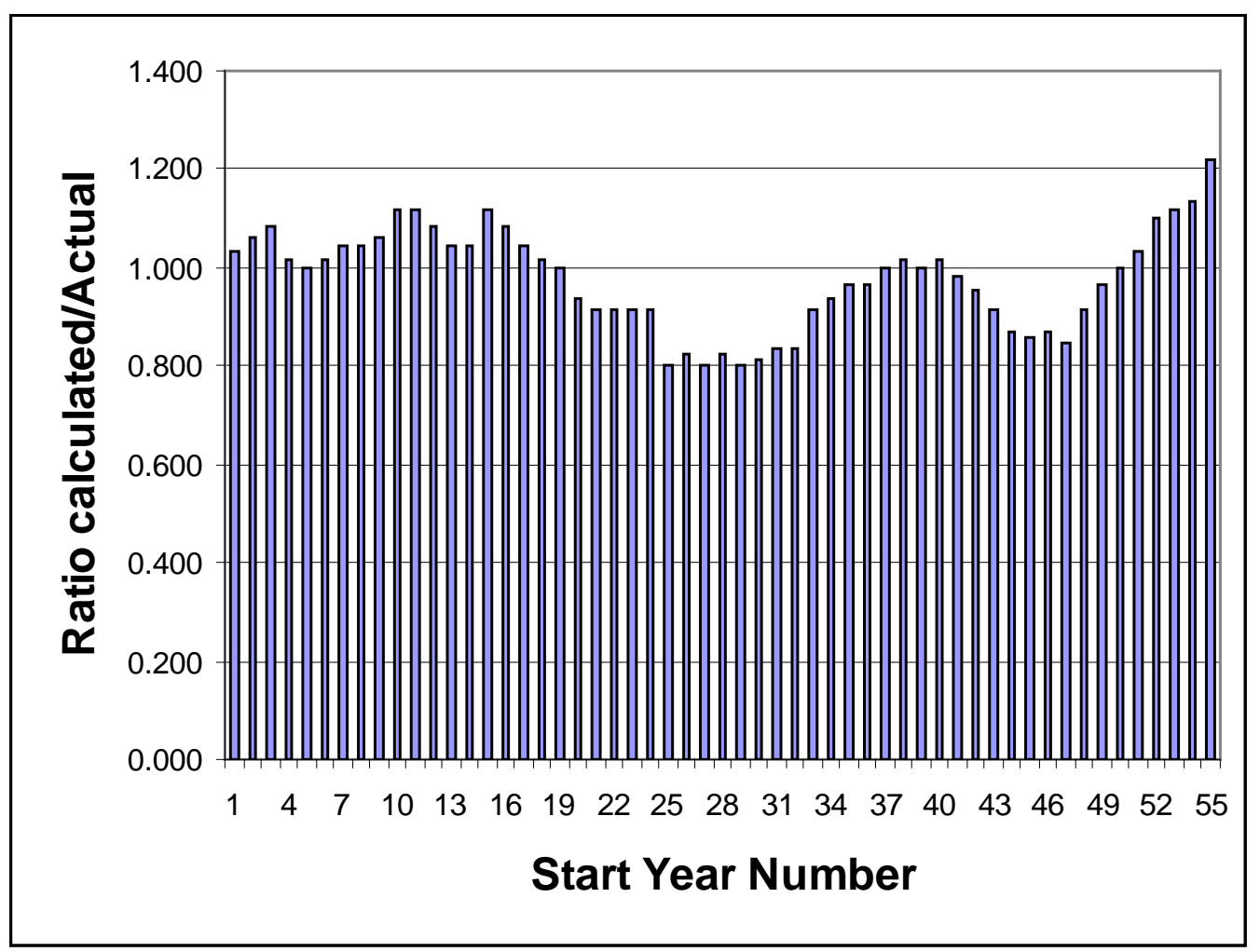

FIG. 4. Ratios of calculated to actual runoff from calibrations of the Curve Number model to 10-year sub-periods of data.

The results are enough to suggest that the variations in calibration from short periods of data are a feature of the data and not of the model. The similarities between Figures 2 and 4 are heartening; however, there are so many different rainfall-runoff models now available that it is impossible to suggest that the results are typical of all models. For the present purpose, the results are sufficient to avoid concerns that they are attributable to the use of a particular model.

\section{Discussion}

The calibration of the two baseflow parameters on all 2-year and 5-year subsets of data showed that BFI and $\mathrm{K}_{\mathrm{b}}$ can be estimated much better than the surface storage parameters from short periods of data. The baseflow parameters depend only on the daily streamflow data and are not affected by any errors in estimation of areal rainfall. Techniques for separation of baseflow and surface runoff have been established and well tested for many 
years (Boughton 1988, Chapman 1999). The results from the present study show that the baseflow characteristics are relatively constant from year to year in the daily runoff record, and that the automatic calibration procedure in the AWBM does not introduce spurious variation. The main problem is the variation in the runoff generation parameters.

The similarity of results from two different rainfall-runoff models, AWBM and the Curve Number, is evidence that the variations in estimates of long term runoff from short periods of record are inherent in the data, and are not an artifact of modelling. The version of the Curve Number used was the original event-based method that is significantly different to the continuous simulation of the AWBM. Although the replication of calculations was limited, the results were sufficient to point the source of variation to the data and not to the model.

Table 1 shows that there is 1 in 5 chance of $\pm 20 \%$ error in the estimation of long term runoff when there is only 2 years of data to calibrate the rainfall-runoff model. The error is very similar even when 5 years of data are available. There are several aspects of the results in Table 1 that are specific to the Snowy Creek data, as follows:

- Figure 2 shows an extended period in the data, starting in year 17 and extending to year 49, when calibrations based on a subset will underestimate the long term runoff. The periods when subsets of data will overestimate the long term runoff are split between the start and end of the data set. The consequence is that the probability of underestimation of long term runoff is high even when subsets of 20 and 30 years are available for calibration, whereas the probability of overestimation decreases as the length of data for calibration increases.

- The separation of the periods producing under and over estimation of long term runoff results in flattening of the ends of the frequency distribution (Figure 3). This flattening has the consequence that there is only a little difference among the ranges of probability 0.025 to $0.975,0.05$ to 0.95 and 0.10 to 0.90 . This results in similar ranges of error in Table 1 for the different ranges of probability.

- Because of the separation of the periods producing under and over estimation of long term runoff, there is very little difference in probable error when either 2 years of data or 5 years of data are available for calibration. The probability of overestimation begins to decrease when 10 years of data are available, but the probability of underestimation persists to the 20-year subsets of data. It is highly likely that this lack of sensitivity to the length of data available for calibration is inherent in the Snowy Creek data but might not be so with other data sets.

Evaporation has much less spatial and temporal variability than rainfall; hence the output from rainfall-runoff models is less sensitive to change or errors in evaporation than in rainfall. Chapman (2003) showed that average monthly evaporation can be used as a surrogate for daily evaporation without any significant loss of accuracy in the modelling of runoff. However, the sparse network of point measurements of pan evaporation and the need to extrapolate to large catchment area provides some uncertainty. 
The most probable reason for variations in the calibration of the AWBM is the inevitable errors in estimating areal rainfall over a $407 \mathrm{~km}^{2}$ catchment from point measurements in a few rain gauges. Over a period of 64 years, the operating rainfall stations change such that there are different point measurements available in different periods of the record. Hall and Barclay (1975) reported that "Areal rainfall estimates based on point measurements should only be regarded as an index of the true mean rainfall over a catchment and errors between 10 and 20 per cent can be regarded as normal. Where strong wind effects or mountainous catchments are being experienced, errors up to 60 per cent can be experienced". These ranges of errors in rainfall estimation can easily account for the variations in calibration of the rainfall-runoff models found in this study.

The percent errors in estimates of long term runoff do not translate directly to errors in the safe yield of reservoirs or in probability of failure of a water supply system. The significance of the errors will depend wholly on the purpose and specific application of the modelling. The worst result from use of a short period of data is overestimation of the long term runoff. While there was a bias towards underestimation of long term runoff in the data set used in the study, it is likely that other data sets will produce the opposite bias. The Snowy Creek data were of good quality and there was no evidence to suggest that it was abnormal or unusual in any way.

\section{Conclusions}

There are two significant results from the study of how calibration of a rainfall-runoff model with a short period of data affects the estimate of long term runoff:

- The potential errors from use of short periods of data are significant, in the order of $20 \%-30 \%$ when 2 to 5 years of data were available for calibration

- Results seem to be dependent on the specific data set but not much on the rainfallrunoff model used

A significant result is that baseflow parameters can be calibrated with little error from short periods of data. The problem can be focused on the runoff generating parameters.

Because the characteristics of the data have a big influence on the results, there is an obvious need for repetition of the study with other data sets. There is no shortage of other data sets with at least the 64 years of data used in the present study; however, the method is laborious and it would be optimistic expect a rush of other studies to extend the results. The main hope is that the calculations can be automated to reduce the labor content and allow a group of data sets to be studied.

\section{References}

Australian Bureau of Meteorology (2001). "Climate Atlas of Australia Evapotranspiration.” Bureau of Meteorology, Melbourne. 
Boughton, W. C. (1988). "Partitioning streamflow by computer." Institution of Engineers, Australia, Civil Engineering Trans., CE30 (5), 285-291.

Boughton, W. C. (2004). “The Australian water balance model”. Environmental Modelling \& Software, 19, 943-956.

Boughton, W. C. (2005). "Catchment water balance modelling in Australia 1960-2004.” Agricultural Water Management, 71, 91-116.

Boughton, W. C. and Chiew, F. (2003). "Calibrations of the AWBM for use on ungauged catchments.” Technical Report 03/15, CRC for Catchment Hydrology, Monash University, 37 pp.

Boughton, W. C. and Droop, O. (2003). "Continuous simulation for design flood estimation - a review.” Environmental Modelling \& Software, 18 (4), 309-318.

Chapman, T. (1999). "A comparison of algorithms for stream flow recession and baseflow separation.” Hydrological Processes, 13, 701-714.

Chapman, T. G. (2003). "Estimation of evaporation in rainfall-runoff models." In: Proceedings MODSIM 2003 International Congress on Modelling and Simulation, vol.1, Modelling and Simulation Society of Australia, 148-153.

Chiew, F. H. and McMahon, T. A. (1991). “The applicability of Morton’s and Penman’s evapotranspiration estimates in rainfall-runoff modelling." Water Resources Bulletin, 27, 611-620.

Chiew, F. H., Peel, M. C. and Western, A. W. (2002). "Application and testing of the simple rainfall-runoff model SIMHYD.” In: V. P. Singh and D. K. Frevert (eds.) 'Mathematical Models of Small Watershed Hydrology and Applications', Water Resources Publications, Littleton, Colorado, (ISBN 1-887201-35-1), 335-367.

Hall, A. J. and Barclay, P. A. (1975). "Methods of determining areal rainfall from observed data." In: T. G. Chapman and F. X. Dunin (eds.) 'Prediction in catchment hydrology', Australian Academy of Science, Canberra, 47-57.

Morton, F. I. (1983). "Operational estimates of actual evapotranspiration and their significance to the science and practice of hydrology.” Journal of Hydrology, 66, $1-76$.

Peel, M. C., Chiew, F. H., Western, A. W. and McMahon, T. A. (2001). "Extension of unimpaired monthly streamflow data and regionalization of parameter values to estimate streamflow in ungauged catchments." Report prepared for the National Land and Water Resources Audit, In:

http://audit.ea.gov.au/anra/water/docs/national/streamflow/streamflow.pdf 
Ponce, V. M. and Hawkins, R. H. (1996). "Runoff curve number: has it reached maturity.” ASCE Journal of Hydrological Engineering, 1 (1), 11-19.

USDA Soil Conservation Service (1985). "Estimation of direct runoff from storm rainfall.” National Engineering Handbook, Hydrology (Chapter 10, Section 4). 